\title{
HLA-DP molecules bind cobalt: a possible explanation for the genetic association with hard metal disease
}

\author{
Ilaria Potolicchio, ${ }^{1,2}$, Alfredo Festucci ${ }^{2}$, Peter Hausler ${ }^{2}$ and Rosa Sorrentino ${ }^{1}$ \\ ${ }^{1}$ Department of Cell Biology and Development, University "La Sapienza", Rome, Italy \\ ${ }^{2}$ Institute of Cell Biology, CNR, Rome, Italy
}

\begin{abstract}
Metal dust inhalation induces an interstitial lung disease which may progress to pulmonary fibrosis (hard metal disease, HMD). Cobalt is believed to be the pathogenic agent of HMD. A strong genetic association of HMD with some HLA-DP alleles has been reported although the role of these molecules in the occurrence of the fibrotic disorder remains unclear. A possible explanation of these findings is that HLA-DP but not other HLA class II molecules can bind cobalt. This could have as a consequence an HLA-DP-mediated specific activation of the immune system. To test this hypothesis, we have set up an in vitro binding assay using ${ }^{57} \mathrm{Co}$ and purified HLA-DP and -DR molecules. The results indicate that HLA-DP but not HLA-DR molecules bind cobalt. Moreover, the presence of HLA-DP Glu $\beta 69$, which is associated with susceptibility to HMD, determines a higher metal uptake. Molecular modelling of HLA-DP2 molecules places the Glu $\beta 69$ residue in a position relevant in determining peptide specificity. The possibility that binding of cobalt by HLA-DP molecules can interfere with their antigen presenting functions is discussed.
\end{abstract}

Key words: HLA-DP / Cobalt / Fibrosis

\begin{tabular}{|ll|}
\hline Received & $25 / 1 / 99$ \\
Revised & $12 / 4 / 99$ \\
Accepted & $12 / 4 / 99$ \\
\hline
\end{tabular}

\section{Introduction}

A first report describing a pulmonary disorder associated with occupational exposure to hard metal dusts was published in 1940 [1]. Since then, a syndrome named "hard metal disease" (HMD) has been characterized in detail and comprises a wide range of clinical signs and symptoms [2-4]. Since HMD is induced by inhalation of cobalt ions, sintered or not with other hard metals, cobalt is considered the main triggering agent [5-7]. Exposure to cobalt dust may produce several respiratory disorders, including upper respiratory tract irritation, asthma, and the interstitial lung disorder which may progress to the pulmonary fibrosis. An important hallmark of HMD is the presence of multinucleate giant cells in the bronchoalveolar lavage, underlying the occurrence of an inflammatory process in the lung tissue [8, 9]. Although the clinical aspects of the disease are well defined,

[l 19234]

Abbreviations: HMD: Hard metal disease CBD: Chronic beryllium disease TCA: Trichloroacetic acid CHS: Contact hypersensitivity

0014-2980/99/0707-2140\$17.50+.50/0 the pathogenesis remains unclear. The possible involvement of immunological mechanisms has been pointed out by the finding of a strong association of HMD with HLA-DP allelic products sharing a Glu residue at position $\beta 69$ [10]. Interestingly, the same association was found in chronic beryllium disease (CBD), suggesting a common pathogenic pathway which might involve a wider range of divalent ions [11]. Accordingly, it has been hypothesized that some metal ions can bind directly HLA-DP molecules and then be presented to the $T$ cells. To explore this possibility, we have performed a direct binding test by using ${ }^{57} \mathrm{CoCl}_{2}$ and purified HLA-DP and -DR molecules and shown that only HLA-DP molecules bind cobalt in a pattern that appears to correlate with susceptibility to HMD [10].

\section{Results}

\subsection{HLA-DP but not -DR molecules bind ${ }^{57} \mathrm{CoCl}_{2}$}

In a previous study, among the HMD-affected individuals, the HLA-DPB $1{ }^{*} 0201\left(\mathrm{Glu}^{+} \beta 69\right)$ allele was found to be increased, whereas -DPB1 ${ }^{\star} 0401$ (Lys $^{+} \beta 69$ ), which is the most common allele in the Caucasoid population, was found to be decreased as compared with an

(C) WILEY-VCH Verlag GmbH, D-69451 Weinheim, 1999 
exposed, healthy population [10]. To investigate whether HLA-DP molecules can bind cobalt, an in vitro system was established using ${ }^{57} \mathrm{CoCl}_{2}$. The method was set up first using different concentrations of BSA, which is a good binder of divalent cations (not shown). The two HLA-DP molecules, *0201 from VBP and ${ }^{*} 0401$ from Co1 cell lines, were then purified and tested in a direct metal binding assay. Concomitantly, HLA-DR molecules from the same two cell lines were also purified and underwent the same procedure. MHC purity was controlled by estimating the protein yield, under denaturing and non-denaturing conditions, on SDS-PAGE performed in parallel to Western blot analysis (data not shown). For each protein preparation, a small volume was iodinated and aliquots corresponding to the same trichloroacetic acid (TCA)-precipitated cpm were used for the binding tests. Fig. 1a shows the densitometric analysis of a representative experiment using this cobalt binding assay.

HLA-DP*0201 molecules bound ${ }^{57} \mathrm{CoCl}_{2}$ at least three times more efficiently than HLA-DP*0401 molecules. The presence of unlabeled $\mathrm{CoCl}_{2}$ or EDTA hindered HLA$\mathrm{DP}^{\star} 0201$ binding. That an equivalent amount of protein preparations was used for each sample was controlled by chemiluminescence as described in Sect. 4 (Fig.1b). Under the same experimental conditions HLA-DR molecules bound ${ }^{57} \mathrm{CoCl}_{2}$ at a very low level. Interestingly, in a previous report it has been shown that $\mathrm{Zn}^{2+}$, a $\mathrm{Co}^{2+}$ equivalent ion, has no binding site in HLA-DR1 molecules [12].

\subsection{Glu $\beta 69$ correlates with a higher cobalt binding}

The HLA-DPB1 gene comprises six hypervariable coding regions, denoted as $A, B, C, D, E$ and F. HLA-DPB1*0201 and DPB $1{ }^{*} 0401$ alleles differ by three of these regions: the conservative substitution Val to Ala at position 36 (B); Asp Glu to Ala Ala at positions 55 and 56 (C); and Glu to Lys at position 69 (D) [13]. Glu as well as Asp are known to be good ligands for $\mathrm{Co}^{2+}$ ions [14]. Thus, in principle, the difference in cobalt binding between DP*0201 and DP*0401 molecules might correlate with either of these two residue substitutions, C or D. The relevance of Glu $\beta 69$ was analyzed testing cobalt binding to $\mathrm{DP}^{\star} 0402$ molecules that differ from HLA-DP*0201 only at this position (Lys instead of Glu). To verify both the state and the amount of the protein preparations used, PAGE of the three (HLA-DP*0201, *0401, *0402) molecules was run under non-denaturing conditions (Fig. 2). A major comparable band is visible at the position expected for the heterodimer in the three samples. The stronger signal present at the origin of the gel represents complexed molecules, an expected feature under the non-denaturing gel electrophoresis conditions $a$

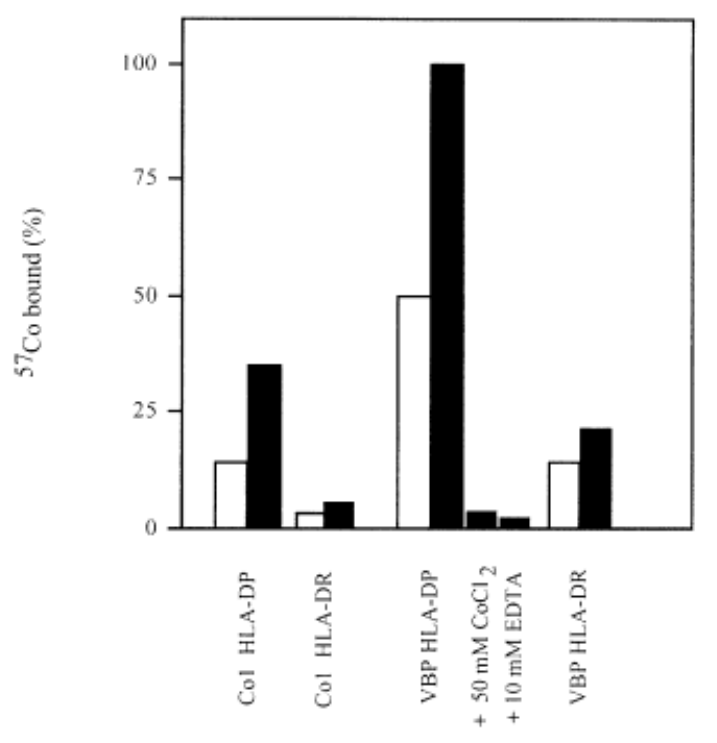

$b$
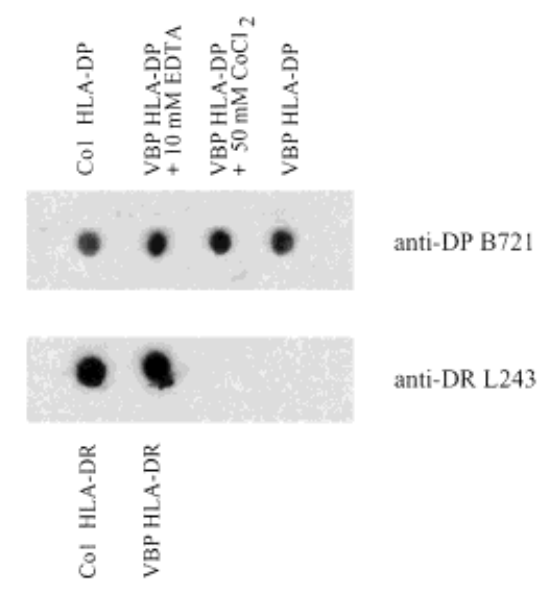

Figure 1. Densitometric analysis of ${ }^{57} \mathrm{CoCl}_{2}$ binding of HLADP and HLA-DR molecules. Protein amounts were normalized by radiolabeling aliquots of purified HLA class II molecules and binding was performed at serial twofold dilutions: $1 \times 10^{6}{ }^{125} \mathrm{I} \mathrm{cpm} \mathrm{(open} \mathrm{bars)} \mathrm{and} 3 \times 10^{6}{ }^{125} \mathrm{I} \mathrm{cpm} \mathrm{(solid} \mathrm{bars).}$ (a) shows the Phospholmager densitometric measurements expressed as percentage of the density given by the $3 \times 10^{6}$ ${ }^{125} \mathrm{I} \mathrm{cpm} \mathrm{equivalent} \mathrm{of} \mathrm{DP*0201} \mathrm{molecules} \mathrm{from} \mathrm{the} \mathrm{VBP} \mathrm{cell}$ line. Cobalt binding was hindered by the presence of $50 \mathrm{mM}$ unlabeled $\mathrm{CoCl}_{2}$ or of $10 \mathrm{mM}$ EDTA (pH 8). (b) shows the equivalent amount of proteins (corresponding to $3 \times 10^{6} 125$ I cpm) spotted on nitrocellulose membrane and treated as above but without ${ }^{57} \mathrm{CoCl}_{2}$ and processed for chemiluminescence detection of proteins as described in Sect. 4.4. 


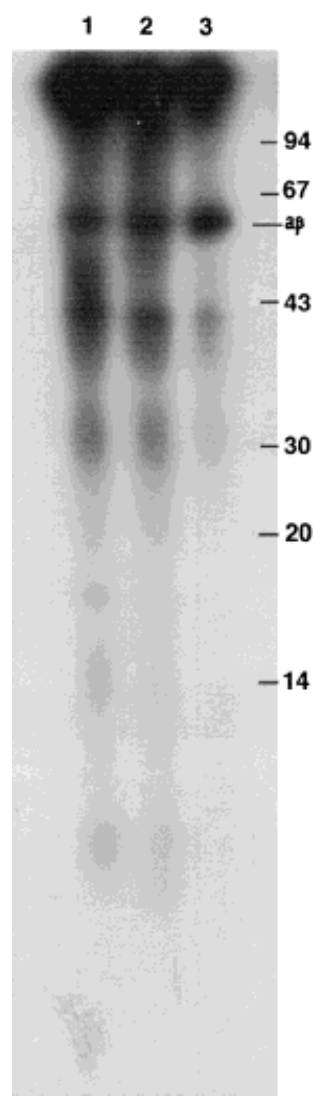

Figure 2. Gel electrophoresis of TCA-precipitated HLA-DP molecules. Immunopurified HLA-DP*0201 (lane 1), *0401 (lane 2) and *0402 (lane 3) molecules were iodine labeled, precipitated and $4 \times 10^{6} \mathrm{cpm}$ were run in each lane in a $12.5 \%$ polyacrylamide gel under non-denaturing conditions. Positions of molecular mass markers phosphorylase $B$ (94 kDa), BSA (68 kDa), ovalbumin (43 kDa), carbonic anydrase $(30 \mathrm{kDa})$, soybean trypsin inhibitor $(20 \mathrm{kDa})$ and $\alpha-$ lactalbumin (14 $\mathrm{kDa})$ are indicated at the right.

used here and verified in this particular case by Western blot (not shown). Equivalent amounts of non-labeled preparations were mixed with ${ }^{57} \mathrm{CoCl}_{2}$. Interestingly, HLA-DP*0402 molecules bound less ${ }^{57} \mathrm{CoCl}_{2}$ than HLADP*0201, thus pointing to Glu $\beta 69$ as a cobalt ligand (Fig. 3a). However, the difference observed between HLA-DP*0402 and HLA-DP*0401 subtypes suggests that also Asp $\beta 55$ and/or Glu $\beta 56$ (Ala Ala in HLA$\mathrm{DP}^{\star} 0401$ molecules) are cobalt ligands contributing one or two additional binding sites. Therefore seems to be there a correlation between the intensity of cobalt uptake and the number of acidic residues in the DP $\beta 1$ domain (Fig. 3b).

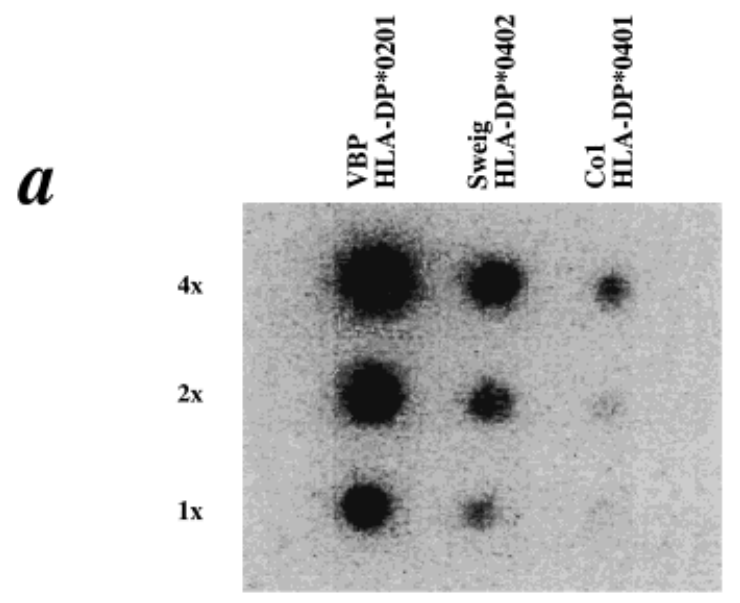

b

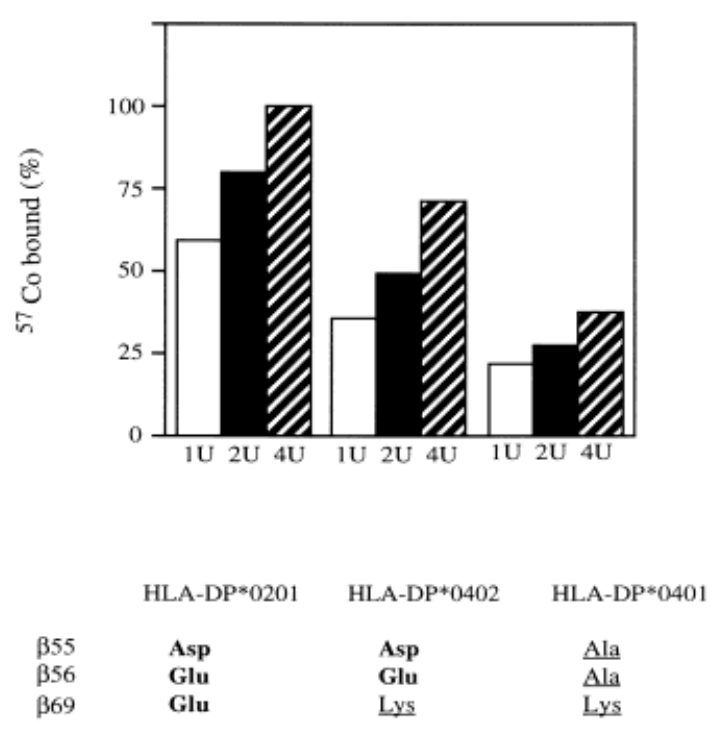

Figure 3. Differential ${ }^{57} \mathrm{CoCl}_{2}$ binding of HLA-DP alleles. The following $B$ cell lines were used: VBP (HLADPB ${ }^{\star} 0201 /{ }^{*} 0201$ ), Sweig (HLA-DPB $\left.1{ }^{*} 0402 /{ }^{*} 0402\right)$, Co1 (HLA-DPB1*0401/*0401). In vitro ${ }^{57} \mathrm{CoCl}_{2}$ binding was performed under the same conditions as in Fig. 1, being defined in this case as $1.8 \times 10^{6} 125$ TCA-precipitated cpm. The autoradiographic image is shown in (a) and the corresponding densitometric value in (b) is expressed as a percentage of the density given by $4 \mathrm{U}\left(=7.4 \times 10^{6}{ }^{125} \mathrm{I} \mathrm{cpm}\right)$ of HLA$\mathrm{DP}^{\star} 0201$ molecules.

\subsection{Localization of the putative cobalt-binding sites by molecular modeling}

Structural and functional studies on HLA-DP molecules have been hampered by the low expression of these molecules on the cell surface and no crystallographic image is available yet. However, HLA-DP2 can be modeled on the HLA-DR1 structure and the location of most residues in the DP $\alpha$ - und $\beta$-chains can be predicted. The 
alignment of -DR and -DP $\beta$ chains implied a two-amino acid shift starting approximately from position $\beta 22$, whereas $\alpha$ chains can be aligned with no amino acid shift. Based on the modeling (Fig. 4), DP $\beta 69$ corresponds to the DR $\beta 71$, a P4 pocket residue that has been shown to contribute to the specificity of bound peptides $[15,16]$. The side chains of DP2 Glu $\beta 69$ and DP2 Asp $\beta 55$ are projected towards the peptide-binding cleft, although they are located in non-contiguous parts of the molecule. DP2 Asp $\beta 55$ is predicted to be localized in the P9 contact region [17]. It is in the proximity of the conserved residue Arg $\alpha 76$ and, similarly to what has been observed in the DR1 structure (Asp $357 /$ Arg $\alpha 76$ ), it might form a salt bridge underneath the bound peptide. The DP2 Glu $\beta 56$ side chain is oriented outside the peptide-binding groove in the proximity of the nonpolymorphic residue Glu $\beta 57$ forming a negatively charged region external to the molecules. It is unlikely that this acidic site is involved in peptide selection.

\section{Discussion}

The mechanisms by which metals induce allergic or autoimmune-like reactions are still obscure. The findings that some metal-related diseases are strongly associ- ated with the HLA-DPB1 locus, whereas some others show no HLA association, suggest that several mechanisms may operate. In this respect, cobalt is particularly interesting since it can induce different pathologies: in the case of metal-specific contact hypersensitivities (CHS), cobalt sensitivity is observed in a high percentage of nickel-sensitive individuals and, in such case, no convincing genetic association has ever been reported. On the contrary, a strong genetic association with some HLA-DP alleles paralleling what has been described in the case of CBD [11] has been reported for HMD, suggesting that $\mathrm{CHS}$ and $\mathrm{HMD}$ originate from different molecular mechanisms.

Several studies have described T cells specific for metals like nickel [18], gold [19], beryllium [20] and cobalt [21], indicating that metal ions can interfere with antigen presentation [22-23].

In the case of nickel-induced allergy, the metal was found to inhibit the reactivity of an antigen-specific $T$ cell clone probably by interacting with the loaded peptide [24]. Given the promiscuity of the HLA class II molecules $[25,26]$, this could explain why those allergies show little or no HLA association [27-29]. HLA-DP molecules bind peptides and they are similar in length and properties to

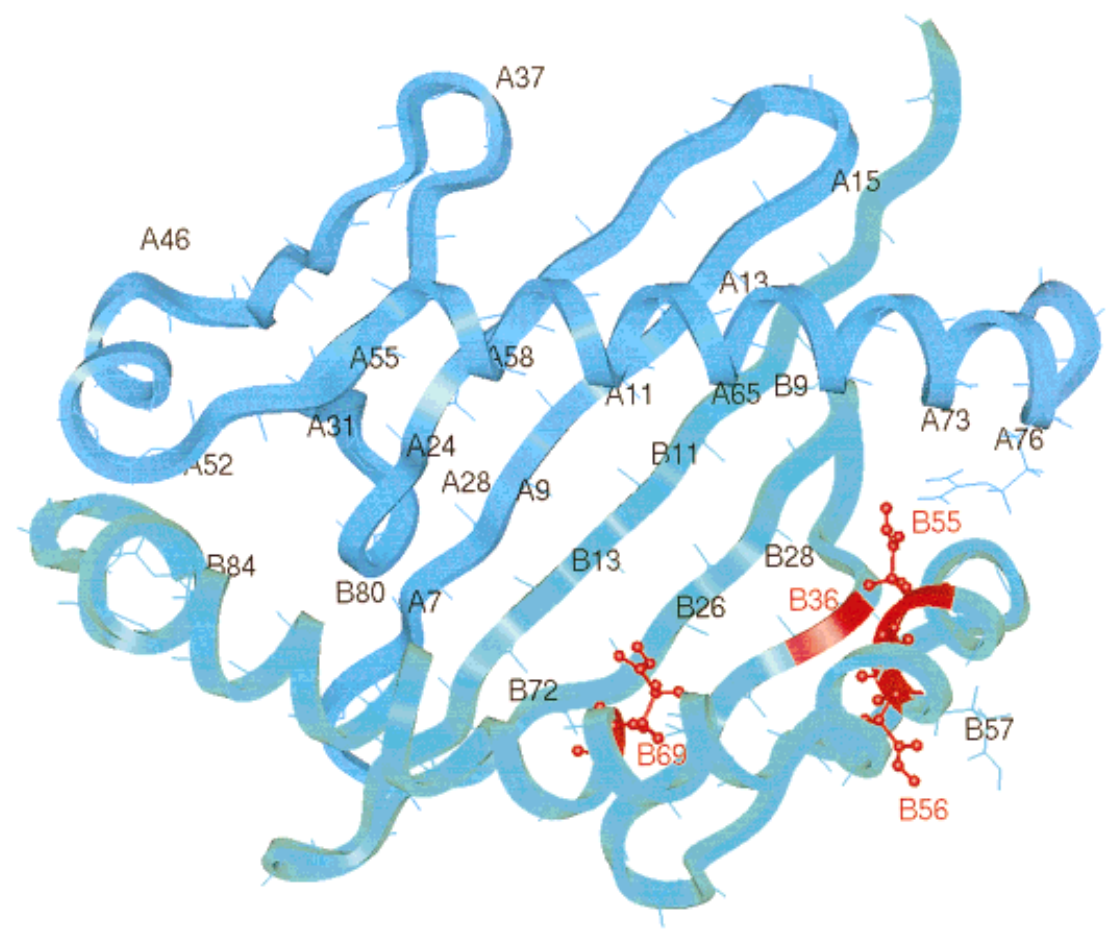

Figure 4. Molecular model of HLA-DP*0201 peptide-binding groove. The protein backbones are overlaid by ribbon representation, the blue parts belong to the $\alpha$ chain and the turquoise parts to the $\beta$ chain, respectively. Sequence positions of some amino acids are indicated, where ' $A$ ' refers to the $\alpha$ chain, ' $B$ ' to the $\beta$ chain, and number 1 is assigned to the amino acid $C$-terminal of the putative signal peptide. Amino acids $\beta 36,55,56$ and 69 are shown in red. The relevant amino acids ( $\beta 55,56$ and 69$)$ are furthermore represented as "ball and stick" models. 
those isolated from HLA-DR and -DQ [30]. The strong association of HMD with HLA-DP Glu $\beta 69$, the experimental observation that cobalt-binding correlates with the number of acidic residues in the HLA-DP groove and the lack of an appreciable binding by HLA-DR all indicate the existence of an alternative pathogenic mechanism by which the direct interaction between cobald and HLA-DP is part of the disease process.

Some features of the HLA-DP-cobalt interaction can be inferred by molecular modeling. Since the more common $\mathrm{Co}^{2+}$ coordination geometry is tetrahedral with an acceptable distance from ligands of approximately $2 \AA$ [30-32], it is evident in the model (Fig. 4) that, when the three polymorphic residues Asp $\beta 55$, Glu $\beta 56$ and Glu $\beta 69$ are present, i. e. in the DP2 molecule, they are too far away to take part in the same ${ }^{57} \mathrm{Co}^{2+}$ binding site. The data suggest instead that there is more than one independent metal binding region in the molecule and Glu $\beta 69$ is likely to contribute one of them. In HLA-DR1 molecules Asp $\beta 57$ (homologous to HLA-DP2 $\beta 55$ ) is engaged in a salt bridge with the facing $\operatorname{Arg} \alpha 76$ and it is resonable to assume that it also occurs between HLA-DP2 Asp $\beta 55-$ Arg $\alpha 76$ facing residues. Since HLA-DR cobalt binding is negligible, it is unlikely that in HLA-DP2 molecules the homologous region is determinant for the metal binding.

Glu $\beta 56$, possibly in cooperation with the closely located Glu $\beta 57$ which is conserved in all DP molecules, might also contribute to an alternative $\mathrm{Co}^{2+}$ pocket, but external to the peptide-binding cleft. Assuming that the HLA class II-peptide-TCR complexes are similar to those formed by HLA class I [34-36], this metal pocket is unlikely to affect the interaction with the TCR. The position Glu $\beta 69$ is predicted to be placed within the groove and it probably contributes to the P4 contact region. Moreover, in vitro binding tests indicate that this residue is responsible for the differences observed between HLA DP*0402 and HLA DP*0201. Therefore Glu $\beta 69$ appears to be critical for both $\mathrm{Co}^{2+}$ binding and peptide presentation.

Once cobalt is bound to HLA-DP molecules, it might induce structural changes of the peptide-MHC complex, but it is also possible that cobalt is required to load a new set of peptides. Cobalt could bind empty HLA-DP molecules, thus producing a charge modification of the P4 pocket, where the Glu $\beta 69$ residue is located. As a consequence, previously ignored tissue-specific self peptides, to which patients have not been made tolerant, can be loaded. In both cases, a specific T cell response might occur which may trigger the tissue distruction preceding fibrosis.
In conclusion, Glu $\beta 69$, although it is not the only ligand for cobalt in the HLA-DP molecule, is likely to be itself a key factor in the pathogenesis of metal-driven autoimmune diseases such as $\operatorname{HMD}[37,38]$.

\section{Materials and methods}

\subsection{Cell lines}

HLA-DP-homozygous cell lines were used. Sweig (HLADRB ${ }^{*} 1101 /{ }^{*} 1101$; HLA-DPB $\left.1{ }^{*} 0402 /{ }^{*} 0402\right)$ was derived from the 10th Histocompatibility Workshop. Co1 and VBP are two EBV-transformed B cell lines generated in our laboratory from $\mathrm{PBL}$ of two healthy donors. The cell lines were HLA-class II typed by genomic DNA typing $[39,40]$ and were HLA-DRB ${ }^{*} 1303 /{ }^{*} 0101$; HLA-DPB $1^{*} 0401 /{ }^{*} 0401$ (Co1) and HLA-DRB1*0401/*0701; HLA-DPB $1{ }^{*} 0201 /{ }^{*} 0201$ (VBP).

\subsection{HLA class II purification}

HLA-DP and -DR proteins were immunoprecipitated from B cell line batches as described by Gorga et al. [17] with minor modifications. Briefly, $300 \mathrm{mg}$ of EBV-transformed human B cell lines were resuspended in a freshly prepared lysis buffer containing $50 \mathrm{mM}$ Tris pH 7.5, 1 \% NP40 (BDH, GB), $0.15 \mathrm{M}$ $\mathrm{NaCl}$ and complete EDTA-free protease inhibitor cocktail tablets (Boehringer Mannheim). Cell lysates were precleared by overnight incubation at $4^{\circ} \mathrm{C}$ with $50 \mu \mathrm{l}$ packed protein ASepharose (Pharmacia Biotech, Uppsala, Sweden). Immunoprecipitations were performed in lysis buffer with anti-DR L243-Sepharose, followed by anti-DP B7/21-Sepharose beads. Each incubation step was for $2 \mathrm{~h}$ at $4^{\circ} \mathrm{C}$. Beads were washed extensively and elution was carried out in $50 \mathrm{mM}$ diethylamine, $10 \%$ glycerol, $0.1 \%$ NP40, pH 11.5. Immunoprecipitates were concentrated using Microcon 30 (Amicon) and resuspended in $100 \mu \mathrm{l} 20 \mathrm{mM}$ Hepes pH 7.2, $0.85 \%$ $\mathrm{NaCl}$ buffer. The purity of $\mathrm{MHC}$ preparation was controlled loading biotinylated proteins on SDS-PAGE under reducing and non-reducing conditions followed by Western blot analysis (Hybond-ECL membrane, Amersham). Protein detection was carried out using peroxidase-streptavidin [Chemiluminescence Blotting Kit (biotin/streptavidin), Boehringer Mannheim].

\section{3 lodination}

Aliquots of the immunoprecipitated HLA-DR and -DP molecules were radioiodinated in $200 \mu \mathrm{l}$ PBS with $30 \mu \mathrm{Ci}{ }^{125}$ (Amersham) and $1 \mathrm{mg}$ lodo-Gen (Pierce) [41]. Samples were TCA precipitated, using $5 \mu \mathrm{g}$ BSA (Sigma) as carrier, and assayed in a $\gamma$-counter. Volumes were adjusted to the same protein concentration on the basis of TCA-precipitable cpm.

Aliquots of labeled proteins were precipitated in the presence of BSA with a mixture of $50 \%$ ethanol/25\% acetone/ 
$25 \%$ methanol for $1 \mathrm{~h}$ at $-80^{\circ} \mathrm{C}$, centrifugated for $20 \mathrm{~min}$ in an Eppendorf centrifuge at $14000 \mathrm{rpm}$, dried and resuspended in $20 \mu \mathrm{l}$ non-reducing SDS sample buffer. Of each sample, $2 \mu \mathrm{l}$ were counted in a $\gamma$-counter and the equivalent of $4 \times 10^{6} \mathrm{cpm}$ was loaded and run on an SDS-12.5\% polyacrylamide gel. Gels were dried and autoradiographed.

\subsection{Cobalt binding assay}

Purified HLA class II proteins, HLA-DP*0201, *0401 and *0402 and HLA-DR, adjusted to the same concentration and resuspended in $200 \mathrm{mM}$ MOPS $\mathrm{pH} 5.1,10 \mathrm{mM} \mathrm{MgCl}_{2}, 10$ $\mathrm{mM} \mathrm{CaCl} 2$, $2 \mathrm{mM}$ CHAPS, were mixed with $0.5 \mu \mathrm{Ci}^{57} \mathrm{CoCl}_{2}$ (Amersham; $6.2 \mathrm{mCi} / \mu \mathrm{g}$ ) in a final volume of $50 \mu \mathrm{l}$. Acidic conditions $(\mathrm{pH} 5.1)$ were used to mimick the HLA-class II peptide loading microenvironment [42-44]. After $1 \mathrm{~h}$ incubation at $37^{\circ} \mathrm{C}$, the samples were passed through a $0.2-\mu \mathrm{m}$ nitrocellulose transfer membrane (Protran Nitrocellulose Membrane, Schleicher and Schuell, Germany) with the MOPS buffer [45]. Under these conditions, only proteinbound ${ }^{57} \mathrm{CoCl}_{2}$ is retained by the membrane. After extensively washing with the binding buffer, filters were subjected to autoradiography on a phosphoimager. A corresponding amount of proteins was spotted on a nitrocellulose membrane and incubated with specific anti-HLA class II mAb (B7/21 and L243) [46-47]. After three washes, horseradish peroxidase-labeled secondary antibody conjugate (Amersham) was added for 30 min. Chemiluminescence was carried out by using $\mathrm{BM}$ chemiluminescence blotting substrate (POD) from Boehringer Mannheim following the manufacturer's instructions. The membranes were exposed to film for $60 \mathrm{~s}$ at room temperature.

\subsection{Molecular modeling of HLA-DP*0201}

Sequence and domain structure information were obtained from the Swiss-Prot database. Sequences corresponding to the extracellular parts of $\alpha$ and $\beta$ chain, respectively, were individually submitted to the Swiss-Model Protein Modelling Server (swissmod@ggr.co.uk) via the "first approach mode". Both resulting models were subsequently resubmitted via the "combine mode", with 1DLH (3D structure of HLA-DR1) as a template [48-50]. The resulting $3 \mathrm{D}$ model of the extracellular domain of HLA-DP2 was processed for representation by Insightll (MSI, San Diego, CA).

Acknowledgments: The authors thank R. Tosi for support and critical reading of the manuscript and R. Butler for helping with molecular modelling. Supported in part by a CNR grant to R. S.

\section{References}

1 Jobs, H. and Ballhausen, C., Powder metallurgy as source of dust from the medical and technical standpoint. Vertrauensarzt Krankenkasse 1940. 8: 142-148.

2 Fischbein, A., Luo, J. C., Solomon, S. J., Horowitz, S., Hailoo, W. and Miller, A., Clinical findings among hard metal workers. Br. J. Ind. Med. 1992. 49: 17-24.

3 Chiappino, G., Hard metal disease: clinical aspects. Sci. Total Environ. 1994. 150: 65-68.

4 Balmes, J. R., Respiratory effects of hard-metal dust exposure. Occup. Med. 1987. 2: 327-344.

5 Lison, D., Human toxicity of cobalt-containing dust and experimental studies on the mechanism of interstitial lung disease (hard metal disease). Crit. Rev. Toxicol. 1996. 26: 585-616.

6 Lison, D., Lawerys, R., Demendts, M. and Nemery, B., Experimental research into the pathogenesis of cobalt/hard metal lung disease. Eur. Respir. J. 1996. 9: 1024-1028.

7 Swennen, B., Buchet, J. P., Stànescu, D., Lison, D. and Lawererys, R., Epidemiological survey of workers exposed to cobald oxides, cobalt salts, and cobalt metal. Br. J. Ind. Med. 1993. 50: 835-842.

8 Davison, A., Haslam, P. and Corrin, B., Interstitial lung disease and asthma in hard-metal workers: bronchoalveolar lavage, ultrastructural, and analytical findings and results of bronchial provocation tests. Thorax 1983. 38: 119-128.

9 Rivolta, G., Nicoli, E., Ferretti, G. and Tomasini, M., Hard metal lung disorders: analysis of a group of exposed workers. Sci. Total Environ. 1994. 150: $161-165$.

10 Potolicchio, I., Mosconi, G., Forni, A., Nemery, B., Seghizzi, P. and Sorrentino, R., Susceptibility to hard metal lung disease is strongly associated with the presence of glutamate 69 in HLA-DP $\beta$ chain. Eur. J. Immunol. 1997. 27: 2741-2743.

11 Richeldi, L., Sorrentino R. and Saltini, C., HLA-DPB1 glutamate 69: a genetic marker of beryllium disease. Science 1993. 262: 242-244.

12 Fraser, J. D., Urban, R. G., Strominger, J. L. and Robinson, H., Zinc regulates the function of two superantigens. Proc. Natl. Acad. Sci. USA 1992. 89: 5507-5511.

13 Angelini, G., Bugawan, T. L., Delfino, L., Erlich, H. A. and Ferrara, G. B., HLA-DP typing by DNA amplification and hybridization with specific oligonucleotides. Hum. Immunol. 1989. 26: 169-177. 
14 Jernigan, R., Raghunathan, G. and Bahar, I., Metal ion binding sites in proteins. Curr. Opin. Struct. Biol. 1994. 4: 256-263.

15 Stern, L., Brown, J. H., Jardetzky, T. S., Gorga, J. C., Urban, R. G., Strominger, J. L. and Wiley, D. C., Crystal structure of the human class II MHC protein HLADR1 complexed with an influenza virus peptide. Nature 1994. 368: 215-221.

16 Brown, J. H., Jardetzky, T. S., Gorga, J. C., Stern, J. L., Urban, R. G., Strominger, J. L. and Wiley, D. C., Three-dimensional structure of human class II histocompatibility antigen HLA-DR1. Nature 1993. 364: 33-39.

17 Gorga, J. C., Horejsì, V., Johnson, D. R., Raghupathy, R. and Strominger, J. L., Purification and characterization of class II histocompatibility antigens from a homozygous human B cell line. J. Biol. Chem. 1987. 262: 16087-16094.

18 Sinigaglia, F., Scheidegger, D., Garotta, G., Scheper, R., Pletscher, M. and Lanzavecchia, A., Isolation and characterization of $\mathrm{Ni}$ specific $\mathrm{T}$ cell clones from patients with Ni-contact dermititis. J. Immunol. 1985. 135: 3929-3931.

19 Romagnoli, P., Labhardt, A. M. and Sinigaglia, F., Gold specific $T$ cells in rheumatoid arthritis patients treated with gold. J. Clin. Invest. 1992. 89: 254-258.

20 Saltini, C., Winestck, K., Kirby, M., Pinkston, P. and Crystal, R. G., Maintenance of alveolitits in patients with chronic beryllium disease by bereyllium-specific helper T. cells. N. Engl. J. Med. 1989. 320: 1103-1109.

21 Moulon, C., Vollmer, J. and Weltzien, H. U., Characterization of processing requirements and metal crossreactivities in $\mathrm{T}$ cell clones from patients with allergic contact dermatitis to nickel. Eur. J. Immunol. 1995. 25: 3308-3315.

22 Sinigaglia, F., The molecular basis of metal recognition by T cells. J. Invest. Dermatol. 1994. 102: 398-401.

23 Griem, P., Wulferink, M., Sachs, B., Gonzales, J. B. and Gleichmann, E., Allergic and autoimmune reactions to xenobiotics: how do they arise? Immunol. Today 1998. 136: 133-141.

24 Romagnoli, P., Laabhardt, A. M. and Sinigaglia, F., Selective interaction of $\mathrm{Ni}$ with an MHC-bound peptide. EMBO J. 1991. 10: 1303-1306.

25 Chicz, M. R., Urban, R. G., Gorga, J. C., Vignali, D. A., Lane, W. S. and Strominger, J. L., Specificity and promiscuity among naturally processed peptides bound to HLA-DR alleles. J. Exp. Med. 1993. 178: 27-47.

26 Southwood, S., Sidney, J., Kondo, A., del Guercio, M. F., Appella, E., Hoffmann, S., Kubo, R. T., Chesnut, R. W., Grey, H. M. and Sette, A., Several common HLA-
DR types share largely overlapping peptide binding repertoires. J. Immunol. 1998. 160: 3363-3373.

27 Emtestam, L., Zetterquist, H. and Olerup, O., HLA-DR and -DP alleles in nickel, chromium, and/or cobaltsensitive individuals: genomic analysis based on restriction fragment length polymorphisms. J. Invest. Dermatol. 1993. 100: 271-274.

28 Fisher, T., Rystedt, I., Safwenberg, J. and Egle, I., HLA-A, -B, -C and -DR antigens in individuals with sensitivity to cobalt. Acta Derm. Venereol. (Stockh) 1984. 64: 121-124.

29 Cirla, A. M., Cobalt-related asthma: clinical and immunological aspects. Sci. Total Environ 1994. 150: 85-94.

30 Chicz, R. M., Graziano, D. F., Trucco, M., Strominger, J. L. and Gorga, J.C., HLA-DP2. Self Peptide Sequences and Binding Properties. J. Immunol. 1997. 159: 4935-4942.

31 Sadler, P. J., Tucker, A. and Viles, J. H., Involvement of a lysine residue in the $\mathrm{N}$-terminal $\mathrm{Ni}^{2+}$ and $\mathrm{Cu}^{2+}$ binding site of serum albumins. Comparison with $\mathrm{Co}^{2+}, \mathrm{Cd}^{2+}$ and $\mathrm{Al}^{3+}$. Eur. J. Biochem. 1994. 220: 193-200.

32 Salgado, J., Jiménez, H. R. and Moratal, M., Paramagnetic Cobalt and Nickel Derivatives of Alcaligenes denitrificans Azurin and Its M121Q Mutant. A ${ }^{1} \mathrm{H}$ NMR Study. Biochemistry 1996. 35: 1810-1819.

33 Qiu, X., Pohl, E., Holmes, R. K. and Hol, W. G., HighResolution Structure of the Diphtheria Toxin Repressor Complexed with Cobalt and Manganese Reveals an SH3-like Third Domain and Suggests a Possible Role of Phosphate as Co-corepressor. Biochemistry 1996. 35: 12292-12302.

34 Garboczi, D. N., Ghosh, P., Utz, U., Fan, Q. R., Biddison, W. E. and Wiley, D. C., Structure of the complex between human T-cell receptor, viral peptide and HLAA2. Nature 1996. 384: 134-141.

35 Garcia, K. C., Degano, M., Stanfield, R. L., Brunmark, A., Jackson, M. R., Peterson, P. A., Teyton, L. and Wilson, I. A., An $\alpha \beta$ T Cell Receptor Structure at $2.5 \AA$ and Its Orientation in the TCR-MHC Complex. Science 1996. 274: 209-219.

36 Ding, Y. H., Smith, K. J., Garboczi, D. N., Utz, U., Biddison, W. E. and Wiley, D. C., Two Human T Cell Receptors Bind in a Similar Diagonal Mode to the HLAA2/Tax Peptide Complex Using Different TCR Amino Acids. Immunity 1998. 8: 403-411.

37 Goldman, M., Druet, P. and Gleichmann, E., TH2 cells in systemic autoimmunity: insights from allogeneic disease and chemically-induced autoimmunity. Immunol. Today 1991. 12: 223-227.

38 Griem, P. and Gleichmann, E., Metal ion induced autoimmunity. Curr. Opin. Immunol. 1995. 7: 831-838. 
39 Sorrentino, R., Potolicchio, I., Ferrara, G. B. and Tosi, R., A new approach to HLA-DPB1 typing combining DNA heteroduplex analysis with allele-specific amplification and enzyme restriction. Immunogenetics 1992. 36: 248-254.

40 D'Amato, M. and Sorrentino, R., A simple and economical DRB1 typing procedure combining groupspecific amplification, DNA heteroduplex and enzyme restriction analysis. Tissue Antigens 1994. 43: 295-301.

41 Fraker, P. J. and Speek, J. C., Protein and cell membrane iodinations with a sparingly soluble chloroamide, 1,3,4,6-tetrachloro-3 $\alpha, 6 \alpha$-diphenylglycoluril. Biochem. Biophys. Res. Commun. 1978. 80: 849-857.

42 Tulp, A., Verwoer, D., Dobberstein, B., Ploegh, H. L. and Pieters, J., Isolation and characterization of the intracellular MHC class II compartment. Nature 1994. 369: 120-126.

43 West, A. M., Lucocq, J. M. and Watts, C., Antigen processing and class II MHC peptide-loading compartments in human B-lymphoblastoid cells. Nature 1994. 369: 147-151.

44 Wolf, P. R. and Ploegh, H. L., How MHC class II molecules acquire peptide cargo: biosynthesis and traffiking through the endocytic pathway. Annu. Rev. Cell Biol. 1995. 11: 267-306.

45 Pessi, A., Bianchi, E., Crameri, A., Venturini, S., Tramontano, A. and Sollazzo, M., A designed metalbinding protein with a novel fold. Nature 1993. 362: 367-369.
46 Robbins, P. A., Evans, E. L., Ding, A. H., Warner, N. L. and Brodsky, F. M., Monoclonal antibodies that distinguish between class II antigens (HLA-DP, DQ, and DR) in 14 haplotypes. Hum. Immunol. 1987. 18: 301-313.

47 Fu, X. T. and Karr, R. W., HLA-DR alpha chain residues located on the outer loops are involved in nopolymorphic and polymorphic antibody-binding epitopes. Hum. Immunol. 1994. 39: 253-260.

48 Peitsch, M. C., Protein modeling by E-mail. Bio/Technology 1995. 13: 658-660.

49 Peitsch, M.C., ProMod and Swiss-Model: Internetbased tools for automated comparative protein modelling. Biochem. Soc. Trans. 1996. 24: 274-279.

50 Guex, N. and Peitsch, M. C., SWISS-MODEL and the Swiss-PdbViewer: An environment for comparative protein modelling. Electrophoresis 1997. 18: 2714-2723.

Correspondence: Rosa Sorrentino, Department of Cell Biology and Development, University "La Sapienza", via degli Apuli, I-1 00185 Roma, Italy

Fax: +39-0-6 49917594

e-mail: Sorrentino@axcasp.caspur.it 